\title{
SAYISAL İMGELER İÇİN PRNU VE CNN TABANLI BÖLGESEL MÜDAHALE TESPITI
}

Ahmet Gökhan POYRAZ*

Alınma:22.01.2019; düzeltme: 23.05.2019; kabul: 30.05.2019

\begin{abstract}
Öz: Sayısal resimler üzerinde yapılan çeşitli oynamaları tespit edebilmek, gelişen yazılımların karmaşıklığından ötürü oldukça zorlaşmaktadır. Bu karmaşıklığa çözüm olarak klasik müdahale tespiti yöntemlerine ek olarak son yıllarda evrişimsel sinir ağı tabanlı yöntemler geliştirilmiştir. Böylelikle çok karmaşık müdahaleleri bile tespit edebilen ağlar eğitilebilmiştir. Bu makalede, küçük boyutlarda pencere kullanarak bölgesel müdahale tespiti yapabilen klasik yöntemlerden olan, kameranın kendisine ait olan sensörlerinden elde edilen parmakizini kullanan sensör tabanlı PRNU(Photo Response Non Uniformity) yöntemi ile yeni bir yaklaşım olan evrişimsel sinir ağı(CNN) tabanlı kamera model sinıflandırıcısı yöntemi karşılaştııılmıştır. Böylelikle hangi yöntemin daha başarılı olduğu detaylıca ortaya koyulmuştur. Toplamda 26 adet kamera modeli ve bu kamera modellerinden seçilen 96 x 96'llk piksel blokları ile eğitilen CNN modeli, hem 96 hem de 128'lik pencere boyutu kullanılarak çalışan PRNU yöntemi ile kıyaslanmıştır. Bu kıyaslama sonucunda bölgesel müdahale tespiti probleminde CNN tabanlı kamera model sınıflandırıcısının PRNU yöntemine göre daha başarılı olduğu gösterilmiştir.
\end{abstract}

Anahtar Kelimeler: Lokal müdahale tespiti, evrişimsel sinir ağı, PRNU, oynanmış bölge tespiti, kamera model sınıflandırıcısı, derin öğrenme

\section{PRNU and CNN Based Local Tamper Detection For Digital Images}

Abstract: Detecting various forgeries on digital images is becoming more difficult due to the complexity of developing software. As a solution to this complexity, in addition to conventional detection methods, convolutional neural network (CNN) based methods have been developed in recent years. Thus, networks capable of detecting even very complex interventions could be trained. In this paper, a new approach to the convolutional neural network $(\mathrm{CNN})$ based camera model classifier method is compared with the sensor-based PRNU (Photo Response Non Uniformity) method, which is one of the classical methods that can detect local detection using small-scale windows. Thus, which method is more successful is revealed in detail. A total of 26 camera models and the CNN model, which was trained with 96 x 96 pixel blocks selected from these camera models, was compared with the PRNU method using both the 96 and 128 window size. As a result of this comparison, $\mathrm{CNN}$ based camera model classifier has been shown to be more successful than PRNU method in the local tamper detection problem.

Keywords: Local tamper detection, convolutional neural network, PRNU, image forgery, camera model classifier, deep learning

\footnotetext{
*Uludağ Üniversitesi, Fen Bilimleri Enstitüsü, Elektronik Mühendisliği, Görükle-Bursa TÜRKIYYE

İletişim Yazarı: Ahmet Gökhan POYRAZ (agpoyraz@gmail.com)
} 


\section{GİRIŞ}

Sosyal medyanın kullanımının artması ve sosyal medya mecralarının çoğalmasıyla birlikte bilgi paylaşımı, özellikle bu sayısal ortamda resim ve video paylaşımını oldukça arttırmıştır. Ancak bu durum internet üzerinde paylaşılan bilgilerin güvenilirliği konusunu tartışmaya açmıştır. Güncel yazılımlar kullanılarak artık bir sayısal resmi manipüle etmek oldukça basit bir işlem haline geldi. Hatta cep telefonlarında artık kolaylıkla manipüle işlemi gerçekleştrilebiliyor. Bu oynamalarda, manipüle ya da filtreleme işlemleri yapılırken kötü niyet taşınmasa bile, başkaları tarafından yanlış işler için kullanılıp kullanılmayacağından emin olamayız. Örneğin bir haber kanalına oynanmış bir resmi gerçekmiş gibi gönderip insanları kandırmak mümkündür. Bu gelişmelerle birlikte adli bilişim alanında resimlerdeki bütünsel veya bölgesel müdahale tespiti oldukça önem kazanmıştır.

Adli bilişim konusunda çalışan araştırmacılar bu probleme çözüm olarak çeşitli yöntemler sunmuştur. Bu yöntemler arasında PRNU tabanlı kaynak cihaz tanıma (Miroslav Goljan ve diğ. 2009 ) yöntemi en önde gelen yöntemlerden biridir. Temel olarak kamera cihazının değişmeyen sensör özelliklerini kullanarak bir sayısal resmin test edilen kamera cihazına ait olup olmadığı basit bir korelasyon formülüyle saptanabilmektedir. Z. Lin ve diğ. (2009) çifte siralı kuantalama tespitini önermişlerdir. Bu yöntemde 8 x 8 piksel blokları kullanılarak çifte JPEG sıkıştırması yapılan resimlerdeki izler tespit edilerek kameraya ait olmayan bölgeler tespit edilmeye çalışılmıştır. Ferrara, P. ve diğ. (2012) resmin çekilmesi işlemi sırasında renkli filtreden geçirilme işleminini baz almıştır. Renk filtresinden kaynaklanan örüntü istatistiğini inceleyerek resim üzerindeki farklı olabilecek olan kısmı bulmayı hedeflemiştir. Krawetz ve di ğ. (2007) bir resmin belirli bölgelerinin diğer bölgelerine göre daha az seviyede JPEG sıkıştırması yapıldığında, bu bölgeyi hata analiz yöntemiyle bulmayı hedeflemişlerdir. Farid (2009), resim üzerindeki düşük JPEG kalitesinde kaydedilen bölgeyi bularak oynanmış bölgeyi tespit etmeyi hedeflemiştir. Temel olarak irdelenen resim ile, resmin farklı seviyede sıkıştırılmış versiyonlarıyla arasındaki karesel farka bakarak bölgesel minimum noktayı bulmayı hedeflemektedir. Dirik, A. E. ve Memon, N. (2009) Bayer örüntüsü içindeki renk filtesini tahmin ederek oynanmış bölge tespiti yapabilen bir yöntem sunmuşlardır. Ye, S. ve diğ. (2007) resim içerisindeki güvenilir bloklardan kuantalama matrisini tahmin ederek JPEG ayrık kosinüs dönüşümü dağılımdaki tutarsız bölgeleri bulabilmektedir.

Son yıllarda derin öğrenme tabanlı yöntemler de adli bilişim alanında kullanılmaya başlandı. Özellikle CNN tabanlı kamera model tanıma çalışmaları Luca Bondi ve diğ. (2017) ve Amel Tuama ve diğ. (2016) ekipleri tarafından yapılmıştır. Bu çalışmalarda derin öğrenme yaklaşımı kullanılarak kamera modellerinde ait özelliklerin evrişimsel sinir ağları tarafından çıkarılması sağlanmış, elde edilen özellikler sınıflandırılarak kamera modelleri arasında sınıflandırma yapabilen derin bir sinir ağı modeli oluşturulmuştur. Böylelikle bir resmin hangi marka ve model kameradan çekildiği tespit edilebilmektedir. Bu yöntemler küçük boyutlu pencereler kullanarak karar verdikleri için(Örn. 64x64 piksel) resmin geneli taranarak oynanmış bölgelerin tespiti mümkündür( Luca Bondi ve diğ. 2017a). Derin öğrenme tabanlı lokal müdahale tespiti uygulamaları da bulunmaktadır. Bayar ve diğ. (2016) genel olarak çalışabilen derin öğrenme tabanlı bir yöntem sunmuştur. Sunduğu yöntem ile belirlenen oynama çeşitlerini öğrenen derin öğrenme tabanlı bir makine eğitmiştir. Luca Bondi ve diğ.(2017-b) elinde bulunan bütün kamera modelleriyle CNN tabanlı bir kamera model sınıflandırıcısı eğitmiştir. Sunmuş olduğu algoritma ile kamera model bilgisine ihtiyaç duyulmadan genel çalışabilen bir lokal müdahale tespit edici geliştirmeyi hedeflemiştir. Benzer şekilde Yaqi Liu ve diğ.(2017) CNN tabanlı oynanmış bölge tespit edici sunmuşlardır. Ancak bu yöntemlerde kamera modeli eğer biliniyorsa çok daha etkili çalıştığı gösterilmiştir.

Bu makalede kamera model tanıma kullanarak bölgesel müdahale tespit etme problemine çözüm olarak sunulan önde gelen yöntemlerden olan PRNU yöntemi ile CNN tabanlı kamera model tanıma kullanılarak yapılan lokal oynama tespiti yöntemi karşılaştırılacaktır. İki yöntemin de kamera model bilgisine ihtiyaç duyması bu karşılaştırmayı yapabilmemize olanak 
sağlamaktadır. Özellikle küçük boyutta pencereler seçilerek bu iki farklı temel yöntemin bölgesel müdahaleleri tespit etmedeki başarısı incelenmiştir. PRNU yönteminin kameranın değişmeyen sensör özelliğini kullanmasına karşın, CNN tabanlı yöntem kameranın renk filtresini baz almaktadır. Hangi özelliğin daha başarılı sonuç ürettiğinin literatürde incelenmemiş olması açısından ve PRNU yönteminden daha iyi çalışabilen bir yöntemin gösterilmesi açısından makale bu alanda yenilik taşımaktadır.

Makalenin gidişatı şu şekildedir: 2. Karşılaştırılacak olan yöntemlerin anlatılması, 3. Kullanılan veri seti ve formatının anlatılması, 4. Deney sonuçlarının sunulması, 5. Sonuç.

\section{KARȘILASTIRILAN YÖNTEMLER VE TEORİK ALTYAPILARI}

\subsection{PRNU Tabanlı Kamera Model Tanıma}

Dijital kameralarda, resmi etkileyen bir takım gürültüler mevcuttur. $\mathrm{Bu}$ gürültülerden bazıları kameranın donanımından, bazıları ise harici olarak dışarıdan kaynaklanabilir. Bir resmin temel olarak çekilme aşaması adım adım Şekil 1'de gösterilmiştir.

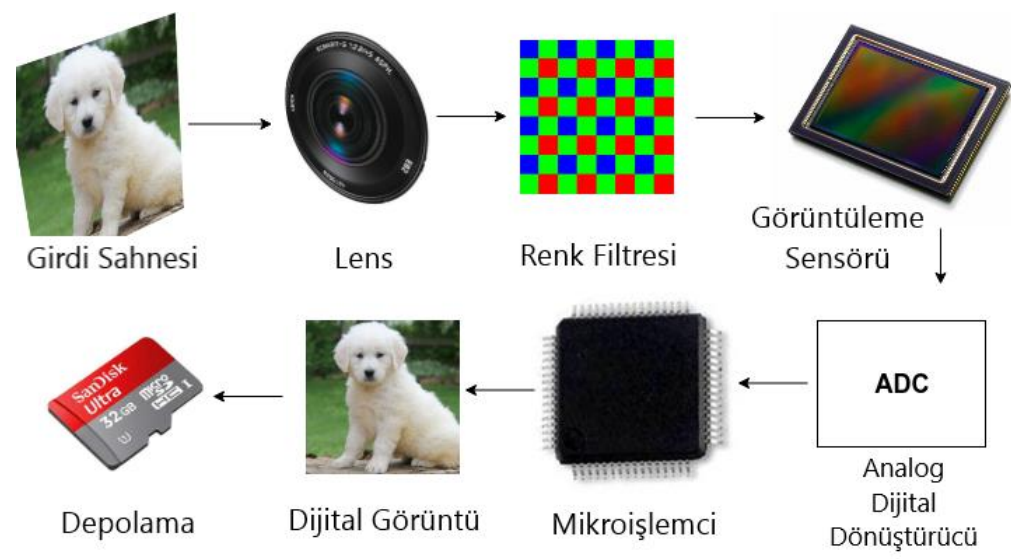

Şekil 1:

Sayısal resmin çekilme aşamaları

Kameranın içerisinde bulunan sensörler kendi yapısından kaynaklanan(materyal özelliği gibi) sebeplerden ötürü gelen 1şı̆̆ ölçerken çok küçük miktarda sabit bir gürültü eklemektedir. $\mathrm{Bu}$ sensörler her kamerada farklı olduğu için bu değişmeyen gürültüler kameranın parmakizini oluşturuyor diyebiliriz. Miroslav Goljan ve diğ. (2009) bu değişmeyen parmakizini tahmin ederek kamera kaynak cihaz tanıma problemine oldukça etkili çalışan bir çözüm sunmuşlardır. Ölçülen 1ş1k miktarı I olmak üzere 1şı̆̆ şu şekilde ifade etmek mümkündür:

$$
I=I_{0}+I_{0} * F+\varnothing
$$

Burada $\mathrm{I}_{0}$ gelen 1şık miktarı, $\mathrm{F}$ sensörden kaynaklanan değişmeyen gürültü miktarı, $\emptyset$ ise harici kaynaklardan gelen değişken gürültüdür. Buradaki değişmeyen F değerinin bulunabilmesi için ölçülen 1şık gürültüden temizlenir. Bu işlem için genellikle Dalgacık (Wavelet) gürültü çıkarıcı (Lukas J. ve diğ. 2006) kullanılmaktadır.

$$
\hat{I}=g u ̈ r u ̈ l t u ̈ \_c ̧ ı k a r ı c l(I)
$$

Denklem 2'den yola çıkarak gürültü = I- Î yapılarak bulunabilir . Ĝ gürültü olmak üzere

$$
\hat{\mathrm{G}} \cong I_{0} * F+\emptyset
$$


olarak yazılabilir. Denklem 3'teki $\emptyset$, değişken değerde olduğu için aynı cihazdan çekilmiş birden fazla resim kullanılarak varyans değeri sıfıra yaklaştırılabilir. Bu sebepten ötürü parmakizi tahmini yapılırken birden fazla resim(ideal sayı 50 ya da yukarısı olarak kabul edilmektedir) kullanılmaktadır. Bu adımdan sonra parmakizi Goljan M. ve dĭg. (2009, Şubat) 'da verilen MLE'ye göre tahmini olarak hesaplanır. Hesaplanan tahmini parmakizi kullanılarak bir resmin test edilen cihaza ait olup olmadığı, $\dot{\mathrm{F}}$ tahmini parmakizi, $I_{t}$ test edilen görüntünün parlaklık değeri, $G$ test edilen resmin gürültüsü olmak üzere korelasyon

$$
\rho=\operatorname{corr}\left(G, I_{t} * \dot{\mathrm{F}}\right)
$$

denkleminden ya da PCE değeri Goljan M. ve diğ. (2009, Şubat) makalesindeki formülden hesaplanir.

Bu çalışmada PRNU yöntemi için öncelikle parmakizi tahmini gerçekleştirildi. Tahmini parmakizi oluşturulurken her bir hedef kamera için daha sonraki aşamalardaki test ve eğitim kısmında kullanılmayan 50'şer adet görüntü seçilmiştir. Seçilen 50'şer adet görüntü kullanılarak hedef kameralar için parmakizi elde edilmiştir. Test edilecek olan her bir bloktan denklem (4)'teki korelasyon formülü kullanılarak $\rho$ korelasyon değeri üretilmiştir. Ancak gürültü matrisi resim içerisinden seçilen her bir bloktan elde edilmek yerine, bloğun çıkarıldığı büyük resimden elde edilmiştir. Bu sayede gürültü daha doğru olacak şekilde çıkarılabilmiştir.

\subsection{Evrişimsel Sinir Ağı Tabanlı Kamera Model Tanıma}

Evrişimsel sinir ağı, yapay sinir ağlarının(YSA) bir alt kolu olarak insan beyninin sinir sistemi yapısından ilham alınarak oluşturulmuş bir yöntemdir. Özellikle obje tanıma, yüz tanıma ve segmente etme problemlerindeki başarısıyla son yıllarda popülerliğini arttırmıştır. Ayrıca adli bilişim alanında da kullanılmaya başlanmıştır. YSA ile CNN mantık olarak aynıdır. YSA'da her bir girdi, kendisi içindeki her bir düğüme ait olan ağırlık değeriyle çarpıldıktan sonra çıktı olarak bir diğer dügüum'e girdi olarak verilir. CNN'nın YSA'dan tek farklı yanı ise bu çarpım işleminde tek bir düğüm yerine filtre şeklinde çarpım olabilmektedir. Yani YSA'da her bir dügümm birbiriyle noktasal olarak çarpılırken, CNN'da belirli bir filtre (Örn. $3 \times 3,5 \times 5$ gibi) boyutuyla çarpım işlemi gerçekleştirilir. $\mathrm{CNN}$, yapısında belirli katmanları bulundurmaktadır. Her bir katman kendisinden bir önceki katmandan gelen çıktıyı girdi olarak almaktadır. Bu girdiyi $\mathrm{E} \times \mathrm{B} \times \mathrm{D}$ (En, Boy, Derinlik) şeklinde gösterecek olursak g girdi, $\mathrm{f}$ filtre ve ç çıktı olmak üzere girdi matrisi $E_{g} \times B_{g} \times D_{g}$ ile filtre matrisi $F_{g} \times F_{g} \times D_{g}$ çarpılarak çıktı matrisini $\mathrm{E}_{\mathrm{c}} \times \mathrm{B}_{\mathrm{c}} \times \mathrm{D}_{\mathrm{c}}$ oluşturmaktadır. Sadece bütün-bağlı katmana gelindiğinde matris formundan vektör formuna dönüşmektedir $(\mathrm{D}=1)$. Bu çalışmada kullanılan $\mathrm{CNN}$ yapısını ve katmanlarını şu şekilde açıklayabiliriz:

-Evrişim Katmanı: Bu katmanda girdi olarak alınan $E_{g} \times B_{g} \times D_{g}$ girdi matrisi ile filtre $F_{g} \times F_{g}$ $\times D_{g}$ matrisi belirlenen kaydırma miktarı $A_{t}$ 'ye göre evrişim çarpımı ile çarpılır. Kaydırma miktarına bağlı olarak çıktının boyutu $\left(E_{g}-F_{g}+1\right) / A_{t}$ formülüne göre değişmektedir. Aynı formülde $\mathrm{E}$ yerine $\mathrm{B}$ yazılarak $\mathrm{B}_{\mathrm{c}}$ de hesaplanır.

-Bölütleme katmanı: Hem yapılan çarpım sayısının azaltılabilmesi hem de girdi boyutunu istenen düzeye indirebilmek için bölütleme katmanı kullanılır. Bu çalışmada maksimum bölütleme kullanılmıştır. Şöyle ki; belirlenen $\mathrm{A}_{\mathrm{t}}$ 'ye göre filtredeki en büyük sayı alınarak çıktı matrisine ya da vektörüne yazılır. Bu katman ile bazen elde edilen özellik matrislerindeki istenmeyen küçük değerler de ortadan kaldırılabilir.

-Bütün-bağlı katman: Girdinin matris boyutundan vektör boyutuna indikten sonraki kısmıdır. Girdi vektörünün noktasal çarpım ile filtre vektörüyle çarpılması işlemi bu katmanda gerçekleştirilir. Burada kaydırma miktarı bulunmamaktadır.

-ReLU katmanı: Doğrusallığı ortadan kaldırabilmek için ReLU (rectifier linear unit) katmanı kullanılır. Bu çalışmada $\mathrm{x}$ düğüm girdisi olmak üzere $\max (0, \mathrm{x})$ fonksiyonu kullanıldı. Oldukça 
basit bir işlem olmasına rağmen modelin doğrusallı̆̆ını değiştirdiği için eğitim başarısını arttırmaktadır.

-Softmax katmanı: Bütün bağlı katmandan elde edilen çıktı vektörünü toplamı 1 olacak şekilde olasılık değerlerine normalize eden katmadır.

-Ara Normalizasyon katmanı: Eğitim esnasında yapılan güncelleme işlemleri neticesinde veri dağılımı değişebilmektedir. Ara normalizasyon katmanı kullanılarak katmanlar arasındaki geçiş esnasında veriler normalize edilir.

-Eksiltme (Dropout) katmanı: Bütün-bağlı katmanda bazı bağlantıların koparılarak modelin eğitim setini aşırı öğrenmesine engel olunur. Bu koparma işlemi rastgele olarak yapılır.

Öğrenme adımında YSA'dakine benzer şekilde düğümlerdeki her bir ağırlığın belirlenen güncelleme algoritmasına göre hatayı en aza indirecek değere getirilmesi amaçlanır. Bu çalışmada hata fonksiyonu olarak softmaxloss fonksiyonu, güncelleme algoritması olarak da dereceli azalma algoritması kullanılmıştır.

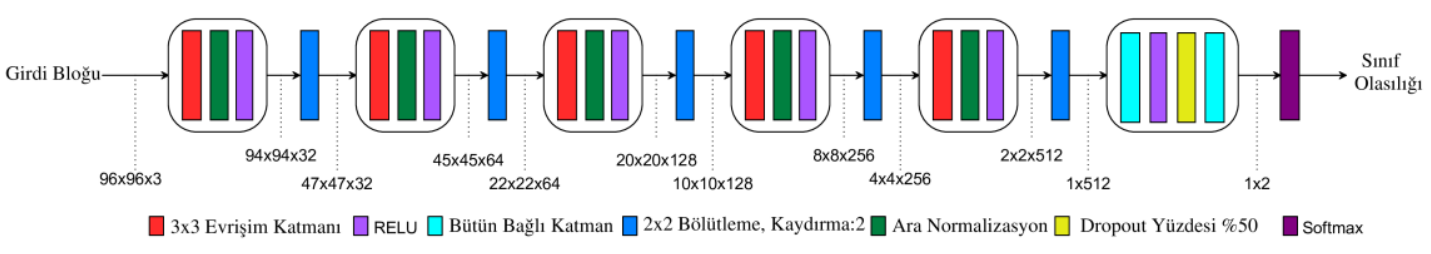

Şekil 2:

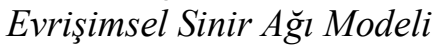

CNN eğitimi yapılırken birçok farklı yapı denenmiştir. Deneysel olarak en iyi sonucu veren model Şekil 2'de gösterilmiştir. Farklı modeller denenirken küçük boyutta filtre kullanıldığında daha başarılı sonuçlar elde edildiği gözlemlenmiştir. CNN modelinde girdi olarak 96 x 96 piksel bloklar kullanılarak eğitim yapılmıștır. Her evrișim katmanından sonra ara normalizasyon katmanı hemen sonrasında da bölütleme katmanı kullanılmıştır. Ek olarak aşırı öğrenmeyi önlemek amacıyla eksiltme katmanı bütün-bağlı katmanda \%50 olacak şekilde eklenmiştir.

PRNU yöntemi kullanılırken kamera cihazına ya da cihazdan elde edilmiş olan parmakizine ihtiyaç duyulmaktadır. Karşılaştırmanın daha adil olabilmesi açısından CNN eğitimi yapılırken kullanılan kamera modelleri hedef kamera ve diğerleri olmak üzere iki sınıftan oluşmaktadır. CNN eğitimi her bir hedef kamera için ayrıca yapılmıştır. Yani eğitilen her bir CNN ağ eğitildiği kamera modelini test etmektedir. Örneğin, Canon IXUS 70 modeli için eğitilen ağ'a 96 x 96 piksel boyutunda bir girdi verildiği zaman, eğitilmiş ağ verilen girdinin Canon IXUS 70 'e ait olup olmadığını yüzdesel olarak üretmektedir. Bu sayede her bir kamera modelinden seçilen cihaz adil bir şekilde karşılaştırılmıştır.

\section{KULLANILAN VERİ SETİ VE EĞİTIM PARAMETRELERI}

$\mathrm{Bu}$ çalışmada literatürdeki en çok kullanılan veri seti olan Dresden veri seti (Gloe, T., \& Böhme, R. (2010, March)) tercih edilmiştir. Bu set içerisinde 26 adet kamera modelinden 74 tane cihaz bulunmaktadır. Eğitimde ve testlerde kullanılmak üzere 26 adet kamera modelinin her birinden 1'er adet cihaz seçilmiştir. Eğitim aşamasında kullanılan hedef(koyu renkli olanlar) ve hedef olmayan kamera modelleri Tablo 1'de gösterilmiştir. 
Tablo 1. Hedef olmayan kamera modelleri

\begin{tabular}{|c|c|c|c|c|}
\hline Marka & Model & $\begin{array}{l}\text { Çözünürlük } \\
\text { [Piksel] }\end{array}$ & $\begin{array}{l}\text { Sensör Boyutu } \\
\text { (inch ya da mm) }\end{array}$ & $\begin{array}{l}\text { Odak Uzaklığ } \\
(\mathrm{mm})\end{array}$ \\
\hline AgfaPhoto & DC-504 & $4032 \times 3024$ & - & 7,1 \\
\hline AgfaPhoto & DC-733s & $3072 \times 2304$ & - & $6,2-18,6$ \\
\hline AgfaPhoto & DC-830i & $3264 \times 2448$ & - & $6,2-18,6$ \\
\hline AgfaPhoto & Sensor 505-X & $2592 \times 1944$ & - & 7,5 \\
\hline AgfaPhoto & Sensor 530s & $4032 \times 3024$ & - & $6,1-18,3$ \\
\hline Canon & Ixus 55 & $2592 \times 1944$ & $1 / 2,5^{\prime \prime}$ & $5,8-17,4$ \\
\hline Casio & EX-Z150 & $3264 \times 2448$ & $1 / 2,5 ”$ & $4,65-18,6$ \\
\hline Kodak & M1063 & $3664 \times 2748$ & $1 / 2,33^{\prime \prime}$ & $5,7-17,1$ \\
\hline Nikon & Coolpix S710 & $4352 \times 3264$ & $1 / 1,72 ”$ & $6,0-21,6$ \\
\hline Nikon & D70/D70s & $3008 \times 2000$ & $23,7 \times 15,6 \mathrm{~mm}$ & $18-200$ \\
\hline Nikon & D70 & $3008 \times 2000$ & $23,7 \times 15,6 \mathrm{~mm}$ & $18-200$ \\
\hline Nikon & D200 Lens A/B & $3872 \times 2592$ & $23,6 \times 15,8 \mathrm{~mm}$ & $18-135 / 17-55$ \\
\hline Olympus & $\mu 1050 \mathrm{SW}$ & $3648 \times 2736$ & $1 / 2,33$ & $6,7-20,1$ \\
\hline Panasonsic & DMC-FZ50 & $3648 \times 2736$ & $1 / 1,8^{\prime \prime}$ & $7,4-88,8$ \\
\hline Pentax & Optio A40 & $4000 \times 3000$ & $1 / 1,7^{\prime \prime}$ & $7,9-23,7$ \\
\hline Pentax & Optio W60 & $3648 \times 2736$ & $1 / 2,3 ”$ & $5,0-25,0$ \\
\hline Praktica & DCZ 5,9 & $2560 \times 1920$ & $1 / 2,5^{\prime \prime}$ & $5,4-16,2$ \\
\hline Rollei & RCP-7325XS & $3072 \times 2304$ & $1 / 2,5$ & $5,8-17,4$ \\
\hline Samsung & L74wide & $3072 \times 2304$ & $1 / 2,5$ & $4,7-16,7$ \\
\hline Samsung & NV15 & $3648 \times 2736$ & $1 / 1,8^{\prime \prime}$ & $7,3-21,9$ \\
\hline Sony & DSC-H50 & $3456 \times 2592$ & $1 / 2,3^{\prime \prime}$ & $5,2-78,0$ \\
\hline Sony & DSC-T77 & $3648 \times 2736$ & $1 / 2,3^{\prime \prime}$ & $6,18-24,7$ \\
\hline Sony & DSC-W170 & $3648 \times 2736$ & $1 / 2,3^{\prime \prime}$ & $5,0-25,0$ \\
\hline
\end{tabular}

Tablo 2. Hedef kamera modelleri

\begin{tabular}{|l|l|l|l|l|}
\hline Marka & Model & $\begin{array}{l}\text { Çözünürlük } \\
{[\text { Piksel] }}\end{array}$ & $\begin{array}{l}\text { Sensör Boyutu } \\
\text { (inch ya da mm) }\end{array}$ & $\begin{array}{l}\text { Odak Uzaklığ1 } \\
(\mathrm{mm})\end{array}$ \\
\hline \hline Canon & Ixus 70 & $3072 \times 2304$ & $1 / 2,5^{\prime}$ & $5,8-17,4$ \\
\hline Fujifilm & FinePix J50 & $3264 \times 2448$ & $1 / 2,5^{\prime}$ & $6,2-31,0$ \\
\hline Ricoh & Capilo GX100 & $3648 \times 2736$ & $1 / 1,75$ ” & $5,1-15,3$ \\
\hline
\end{tabular}

Her bir kameraya ait CNN eğitiminin yapılması oldukça çok işlem maliyeti gerektirdiğinden ötürü 3 adet kamera için eğitim yapılmıştır. Hedef ve hedef olmayan kamera modelleri için PRNU parmakizi çıkarma işlemi her bir cihaz için yaklaşık olarak 5-6 dakika sürmüştür. Ancak asıl işlem maliyeti gerektiren kısım CNN eğitimidir. Yapılan CNN eğitimi her bir cihaz için yaklaşık olarak 2,5 gün sürmüştür. Seçilen bu 3 adet kamera modeli rastgele olarak belirlenmiş̧tir. Diğer kameralar ise CNN eğitiminde diğer sınıfına ait olmak üzere kullanılmıştır. Her bir cihazdan toplamda 50'şer adet resim seçilmiştir. Kamera modellerinin çözünürlük bilgisi modelden modele göre farkl111k gösterdiğinden ötürü her bir resmin ortasından $1080 \mathrm{x}$ 1440 piksellik bölge kesilmiştir. Böylelikle çözünürlük bilgisi sabitlenmiş olmuştur. Ek olarak eğitilen CNN modeli resmin sadece ortasından bloklar alınarak eğitilmesine rağmen, resmin eğitimde kullanılmayan kısımlarında da çalıştığı gösterilmek istendi. Kırpılmış olan her bir resmin rastgele bir bölgesinden CNN eğitiminde kullanmak üzere $96 \times 96$ boyutunda resim blokları çıkarılmıştır. İki sınıfa ait çıkarılan blok sayıları şu şekildedir: yapılacak olan tek bir eğitim için, hedef sınıfındaki kamera modeli için 50 adet resimden toplamda 10 bin blok, hedef olmayan sınıf için her bir kamera modelinden 1 bin blok çıkarılmıştır. Hedef olmayan sınıfa ait toplamda 25 adet kamera bulunduğundan toplam 25 bin blok hedef olmayan sınıf için 
çıkarılmıştır. Böylelikle eğitim yapılırken sınıflara ait veri dağılımı dengesi 10/25 olacak şekilde belirlenmiştir. Yapılan eğitimlerde çıkarılan blokların \%80'i eğitim için \%20'si test için ayırılmıştır. Kullanılan blok sayılarının test/eğitim ve hedef/diğer sınıflarına göre dağılımı Tablo 2'de gösterilmiştir.

Tablo 2.CNN eğitiminde ve testlerde kullanılan toplam blok ve resim sayıları

\begin{tabular}{|l|c|c|c|c|}
\cline { 2 - 5 } \multicolumn{1}{c|}{} & \multicolumn{2}{c|}{ Resim Sayıları } & \multicolumn{2}{c|}{ Blok Sayıları } \\
\cline { 2 - 5 } & Hedef Sinıf & Diğer Sınıf & Hedef Sinıf & Diğer Sınıf \\
\hline \hline Eğitim & 40 & 1000 & 400 bin & 1000 bin \\
\hline Test & 10 & 250 & 100 bin & 250 bin \\
\hline Toplam & 50 & 1250 & 500 bin & 1250 bin \\
\hline
\end{tabular}

Hem resimlerin kırpılması esnasında hem de blok çıkarma işlemi sırasından herhangi bir veri kaybı yaşanmaması açısından bütün kayıt işlemleri kayıpsız mod olan .PNG formatında yapılmıştır. CNN eğitimi yapılırken MatConvNet (Vedaldi, A. ve diğ 2017) kütüphanesi kullanıldı. Momentum olarak 0.9 değeri ve ağırlık zayıflatma değeri $5 \times 10^{-4}$ şeklinde sabitlendi. Toplamda 50 tur döngü ile eğitim gerçekleştirildi.

Eğitimde ve test kısmında kullanılan 50 adet resim seçilirken, içeriği aşırı karanlık ya da aşırı parlak olan resimler hariç tutuldu. Bu işlemin yapılmasındaki amaç resim içerisinde yeterli istatistiki bilgi olmayan resimlerin eğitime dahil edilmeyerek daha kaliteli bir ăg eğitilebilmesidir. Ek olarak benzer sahne içeren içeren resimlerden sadece 1 adet seçildi. Böylelikle eğitilen ağın yalnızca verilen sahneleri öğrenmesi engellenmeye çalışıldı. Yapılan CNN eğitimleri başarılı bir şekilde gerçekleştirilmiştir. Hedef kameralar için eğitilen CNN'ların eğitim başarıları Canon IXUS 70, Ricoh GX100 ve FujiFilm FinePixJ50 için sırasıyla \%85, $\% 99$ ve $\% 95$ 'tir.

\section{KARŞILAŞTIRMA SONUÇLARI VE TARTIŞMA}

Bölüm 2'de detayları anlatılan PRNU tabanlı kamera kaynak tanıma yöntemi ile CNN tabanlı kamera model sınıflandırıcısı belirlenen blok boyutları kullanılarak karşılaştırılmıştır. Bu çalışmada eğitilen CNN modelinin girdisinin $96 \times 96$ olması sebebiyle karşılaştırma boyutu ilk olarak $96 \times 96$ piksel olarak belirlenmiştir. Her bir blok karşılaştırılan bu iki yöntem ile test edilmiştir. Test neticesinde her bir blok için PRNU yönteminden gelen $\rho$ korelasyon değeri ve $\theta$ CNN ağının ürettiği olasılık değeri olmak üzere toplam 2 adet sonuç üretilmiştir. Test işlemine ait süreç Şekil 3'de gösterilmiştir.

Test edilen görüntü bloklarına ait resim ve blok sayıları Tablo 2'de verilmiştir. Elimizde hem hedef kameraya ait hem de diğer sınıfa ait bloklardan elde edilen $\rho$ ve $\theta$ değeri bulunmaktadır. Bu iki değeri karşılaştırabilmek için elde edilen sonuçları ve gerçek değerlerini baz alarak TP, FP, TN, FN değerleri kullanılarak TPR, FPR ve Doğruluk değerleri hesaplanmıştır.

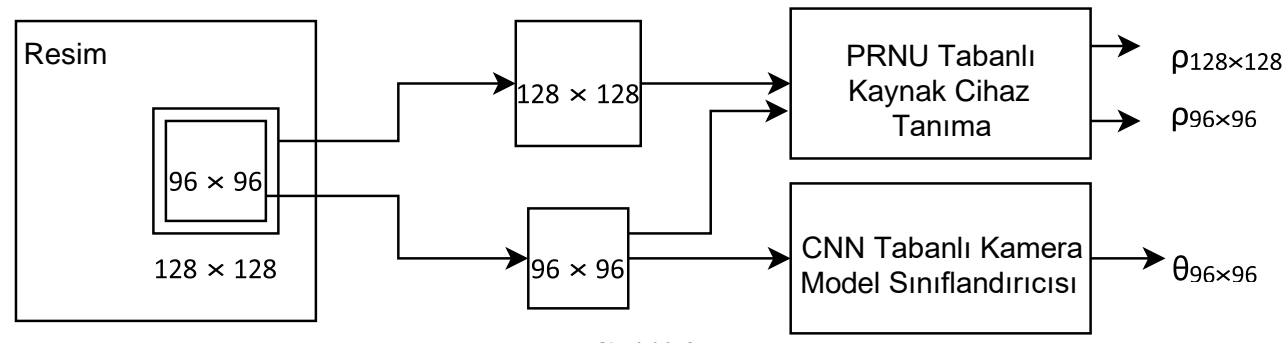

Sekil 3:

Test İşlemi Süreci 
Pozitif hedef sınıfinı, negatif de diğer sınıfı temsil etmek üzere burada

TP: Üretilen değer pozitif ve gerçek değer pozitif ise

FP: Üretilen değer pozitif ve gerçek değer negatif ise

TN: Üretilen değer negatif ve gerçek değer negatif ise

FN: Üretilen değer negatif ve gerçek değer negatif ise değerlerini göstermektedir.

Bu değerler kullanılarak TPR, FPR ve Doğruluk değerleri sırasıyla Denklem 5, 6 ve 7'de ki formüller kullanılarak hesaplanmıştır.

$$
\begin{gathered}
\mathrm{TPR}=\frac{\mathrm{TP}}{\mathrm{TP}+\mathrm{FN}} \\
\mathrm{FPR}=\frac{\mathrm{FP}}{\mathrm{FP}+\mathrm{TN}} \\
\text { Doğruluk }=\frac{\mathrm{TP}+\mathrm{TN}}{\mathrm{TP}+\mathrm{FN}+\mathrm{FP}+\mathrm{TN}}
\end{gathered}
$$

Yapılan deneyin ikinci aşamasında $96 \times 96$ boyutundaki CNN modelinin daha büyük boyuttaki PRNU korelasyon değerine göre karşılaştırılması yapılmak istenmiştir. Bu kısım yapılırken sadece PRNU penceresi $96 \times 96$ 'dan $128 \times 128$ piksel boyutuna çıkarılmıştır. Yani $128 \times$ 128 'lik bloklardan elde edilen $\rho$ değerleri $96 \times 96$ piksellik bloklardan elde edilen $\theta$ değerleriyle karşılaştııılmıştır. Burada karşılaştırmanın adil olabilmesi açısından Çıkarılan $128 \times 128$ piksellik blokların tam orta kısmındaki $96 \times 96$ piksellik bölge $\mathrm{CNN}$ ağına $\theta$ değerlerini üretmesi için verilmiştir. Toplamda 350 bin bloktan hem $\rho$ hem de $\theta$ değeri üretilmiştir.

Tablo 3. Şekil 4,5 ve 6'daki ROC eğrilerinin alt kısmında kalan alan değerleri

\begin{tabular}{|l|c|c|c|}
\cline { 2 - 4 } \multicolumn{1}{c|}{} & \multicolumn{2}{c|}{ PRNU } & CNN \\
\hline \hline Kamera Ad1 & $96 \times 96$ & $128 \times 128$ & $96 \times 96$ \\
\hline Canon IXUS 70 & 0,920 & 0,958 & 0,890 \\
\hline FujiFilm FinePixJ50 & 0,856 & 0,908 & 0,992 \\
\hline Ricoh GX100 & 0,722 & 0,779 & 0,963 \\
\hline
\end{tabular}

Tablo 4. En yüksek Doğruluk değerini veren eşikleme değeri için hesaplanan TPR, FPR ve Doğruluk değerleri

\begin{tabular}{|l|c|c|c|c|c|c|c|c|c|}
\cline { 2 - 10 } \multicolumn{1}{c|}{} & \multicolumn{3}{c|}{ TPR } & \multicolumn{3}{c|}{ FPR } & \multicolumn{3}{c|}{ Doğruluk } \\
\cline { 2 - 10 } \multicolumn{1}{c|}{} & $\begin{array}{c}\text { CNN } \\
96\end{array}$ & $\begin{array}{c}\text { PRNU } \\
96\end{array}$ & $\begin{array}{c}\text { PRNU } \\
128\end{array}$ & $\begin{array}{c}\text { CNN } \\
96\end{array}$ & $\begin{array}{c}\text { PRNU } \\
96\end{array}$ & $\begin{array}{c}\text { PRNU } \\
128\end{array}$ & $\begin{array}{c}\text { CNN } \\
96\end{array}$ & $\begin{array}{c}\text { PRNU } \\
96\end{array}$ & $\begin{array}{c}\text { PRNU } \\
128\end{array}$ \\
\hline $\begin{array}{l}\text { Canon } \\
\text { IXUS 70 }\end{array}$ & 0,95 & 0,95 & $\mathbf{0 , 9 6}$ & 0,31 & 0,30 & $\mathbf{0 , 2 0}$ & 0,87 & 0,87 & $\mathbf{0 , 9 1}$ \\
\hline $\begin{array}{l}\text { FujiFilm } \\
\text { FinePixJ50 }\end{array}$ & $\mathbf{0 , 9 7}$ & 0,94 & 0,93 & $\mathbf{0 , 1 1}$ & 0,73 & 0,61 & $\mathbf{0 , 9 5}$ & 0,74 & 0,77 \\
\hline $\begin{array}{l}\text { Ricoh } \\
\text { GX100 }\end{array}$ & $\mathbf{0 , 9 8}$ & 0,93 & 0,95 & $\mathbf{0 , 0 4}$ & 0,44 & 0,34 & $\mathbf{0 , 9 7}$ & 0,82 & 0,86 \\
\hline
\end{tabular}

Test kümesinin oldukça geniş olması yapılan testin başarısını daha iyi ortaya koymaktadır. Her bir cihazın testinde kullanılan 350 bin adet $96 \times 96$ piksel boyutundaki bloklar ile Çalışma Karakteristikleri elde edilmiştir. Elde edilen Çalışma Karakteristiği eğrileri Şekil 4, 5 ve 6 'da ve bu eğriler altında kalan alan bilgisi Tablo 3'de verilmiştir. Ayrıca Tablo 4'te, Şekil 4, 5 ve 
6'daki Çalışma Karakteristiği eğrilerinden en iyi eşikleme değeri seçilerek hesaplanan TPR, FPR ve Doğruluk değerleri verilmiştir. Tablo 3'deki çalışma karakteristiği eğrilerinin altında kalan alan ve Tablo 4'teki doğruluk yüzdelerine göre 2 kamera cihazında CNN tabanlı yöntem, geriye kalan 1 adet cihazda ise PRNU tabanlı yöntemden daha iyi çalışmaktadır. PRNU yönteminin daha iyi çalıştığı cihazda bile PRNU yöntemi, CNN tabanlı yönteme göre çok az bir farkla üstünlük sağlamaktadır. Ek olarak CNN tabanlı yöntemin iyi olduğu kamera cihazlarında CNN tabanlı yöntem PRNU yönteminin $128 \times 128$ 'lik pencere boyutunda elde ettiği sonuçlardan bile daha iyi performans göstermiştir.

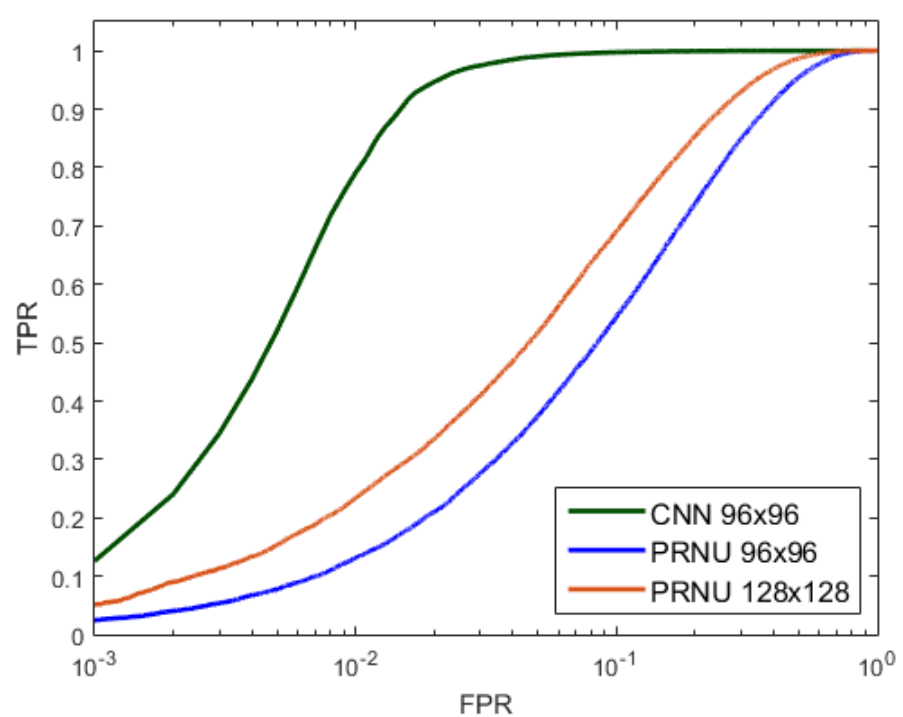

Şekil 4:

Ricoh'a ait $R O C$

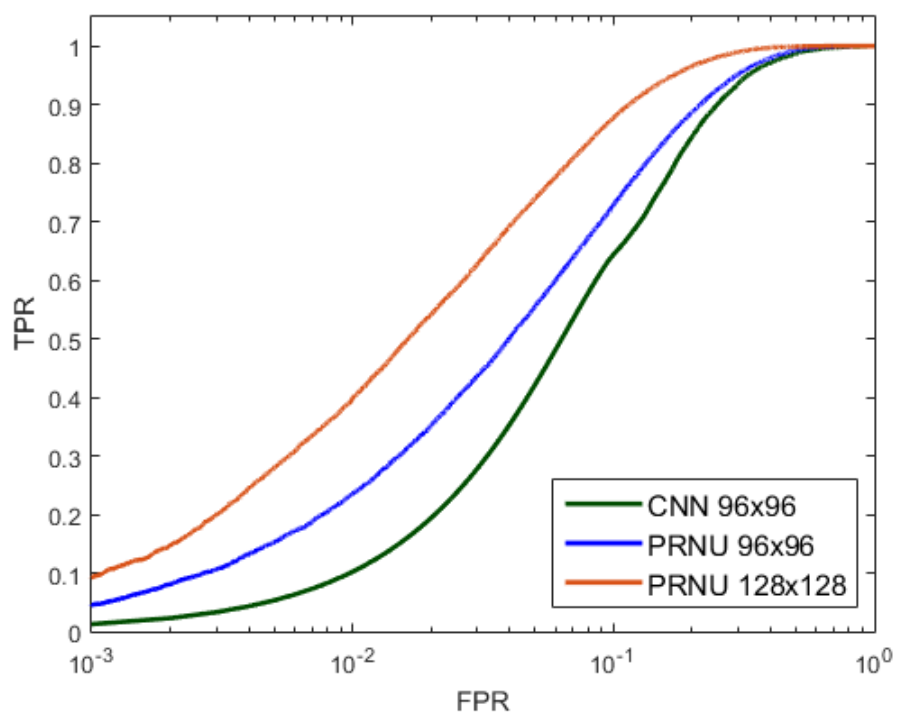

Şekil 5:

Canon'a ait ROC 


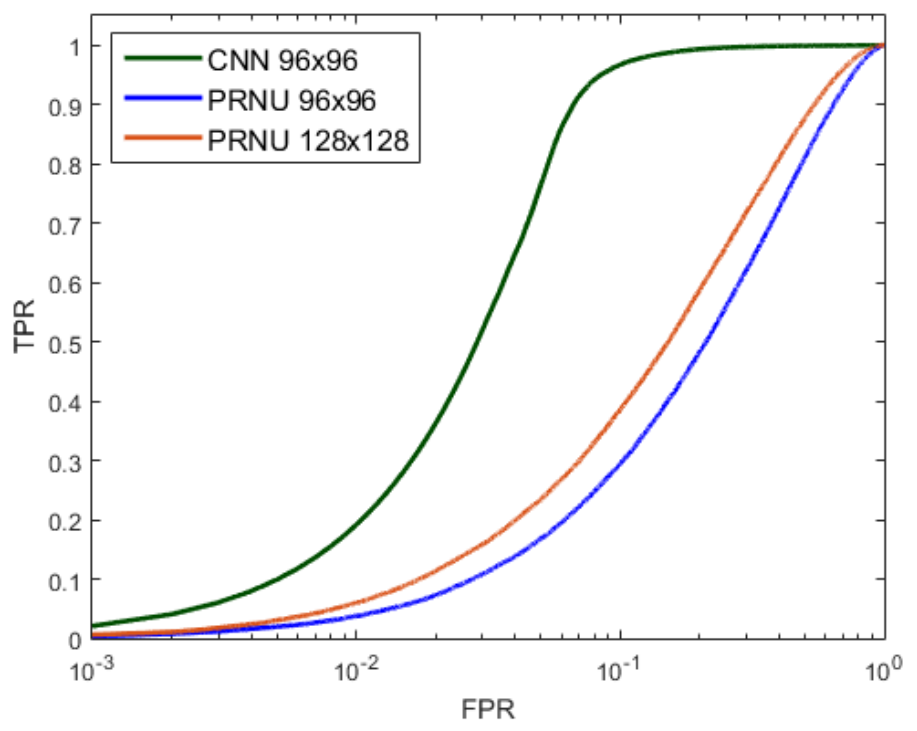

Şekil 6:

Fuji'ye ait ROC

Kamera cihazlarının hepsinden bazen iyi bir parmakizi tahmin edilememektedir. $\mathrm{Bu}$ durumlarda CNN tabanlı yöntem kullanmak daha doğru sonuçlar üretecektir. Oynanmış resimlerin olduğu bir görüntü kümesinde test yapmak karşılaştırma açısından daha iyi olacak olsa da işlem maliyeti açısından çok fazla zaman alacağı için blok bazlı karşılaştırma yapılmıştır. Ancak yöntemlerin nasıl çalıştığını görsel olarak gösterebilmek için . $400 \times 400$, $200 \times 200$ ve $100 \times 100$ boyutlarında sırasıyla ağır, orta ve hafif olacak şekilde oynamalar için yöntemlerin sonuçları Şekil 7, 8 ve 9'da gösterilmiştir. Şekil 7, 8 ve 9'da sırasıyla $400 \times$ $400,200 \times 200$ ve $100 \times 100$ boyutunda bir bölge diğer sınıfına ait olan kameralardan kesilip hedef kamera resimleri üzerinde rastgele bir kısma yapıştırılmıştır.

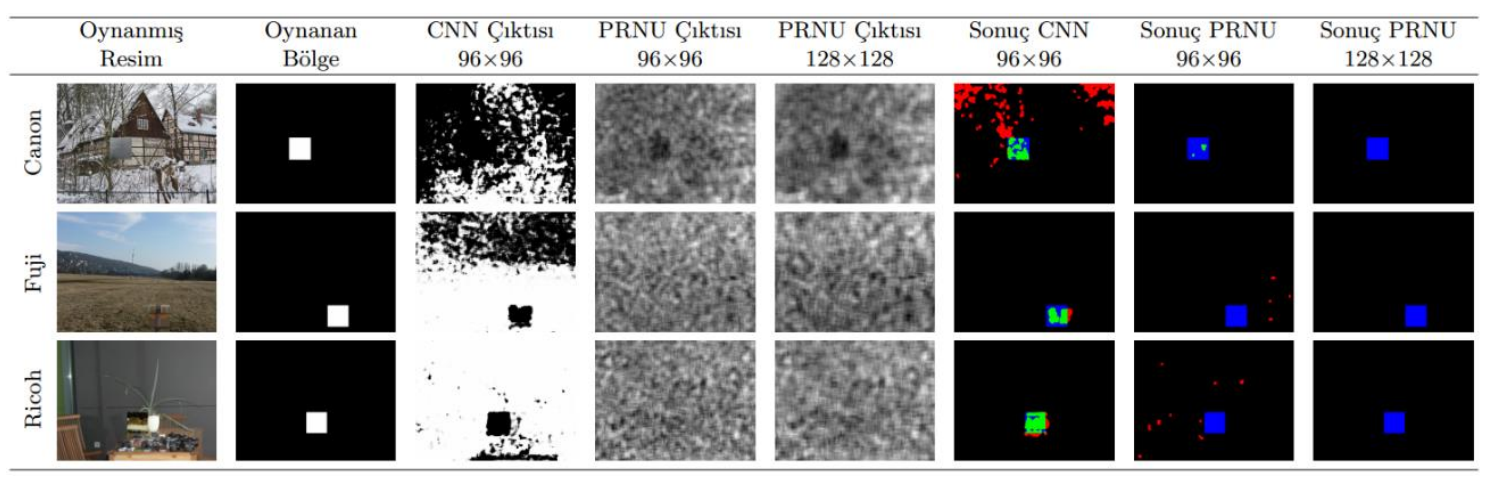

Sekil 7

Test edilen yöntemlerin $400 \times 400$ oynama boyutu için sonuç çıktıları. Sonuç kısmında uygulanan eşikleme değeri çalışma karakteristiği eğrilerinden yüzde 1 FP olacak şekilde belirlenmiştir. 


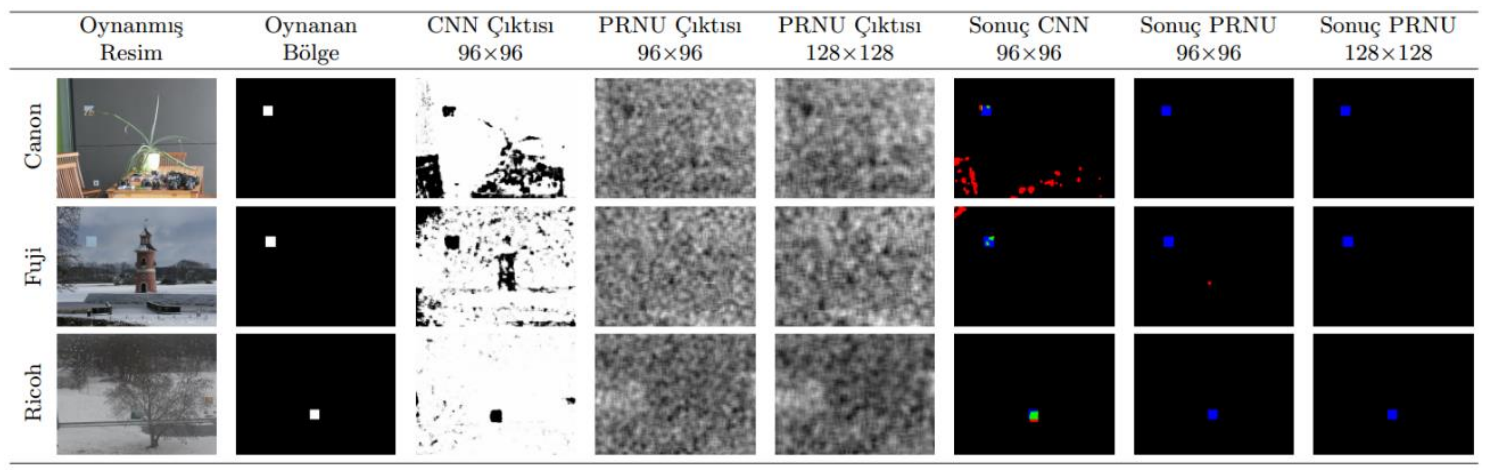

Şekil 8:

Test edilen yöntemlerin $200 \times 200$ oynama boyutu için sonuç çıktıları. Sonuç kısmında uygulanan eşikleme değeri çalışma karakteristiği eğrilerinden yüzde 1 FP olacak şekilde belirlenmiştir.

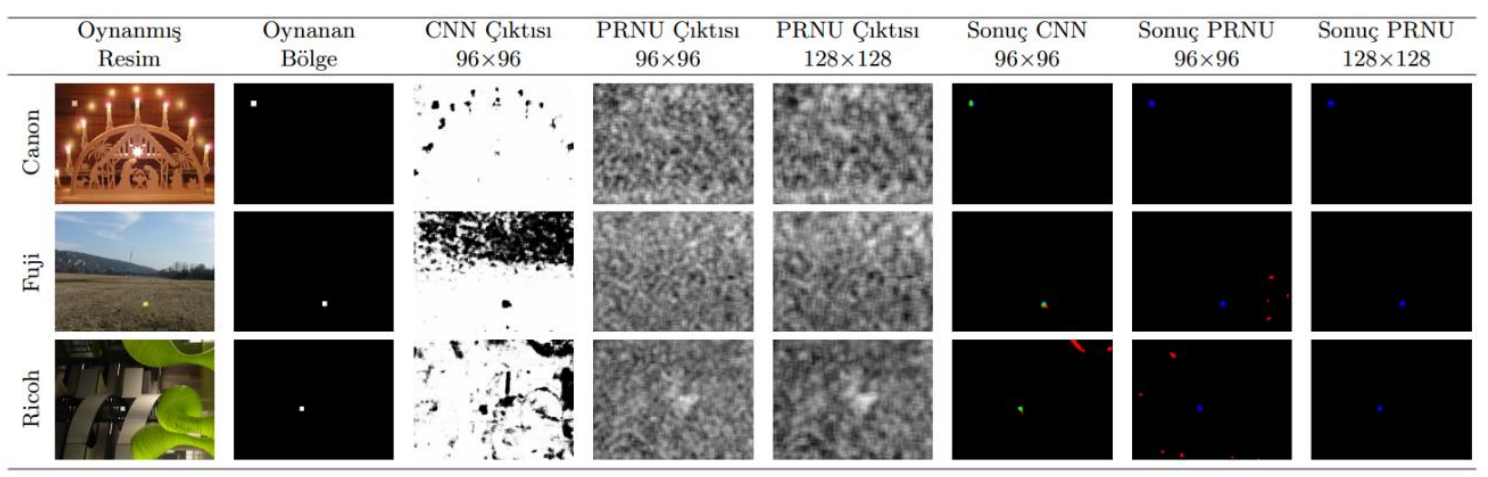

Şekil 9:

Test edilen yöntemlerin $100 \times 100$ oynama boyutu için sonuç çıktıları. Sonuç kısmında uygulanan eşikleme değeri çalışma karakteristiği eğrilerinden yüzde 1 FP olacak şekilde belirlenmiştir.

\section{SONUÇ}

$\mathrm{Bu}$ çalı̧̧mada bölgesel müdahale tespiti yapan temel yöntemlerden PRNU tabanlı kamera kaynak tanıma yöntemi ile evrişimsel sinir ağı tabanlı kamera model tanıma yöntemi karşılaş̧ırılmıştır. Literatürde ayrı ayrı olarak iki yöntem de karşılaştırılmıştır. İki yöntem de kendi alanlarlarında öncü olmaktadırlar. Ancak bu iki yöntemin birbiriyle olan karşılaştırılması bulunmamaktadır. PRNU yöntemi kamera cihazının değişmeyen sensör özelliklerine dayanırken, CNN tabanlı yöntem kamera cihazının renk filtresini temel almaktadır. PRNU yöntemi kullanılarak yapılan oynanmış bölge tespiti seçilen pencere boyutuna göre farklılık göstermektedir. Seçilen pencere boyutu büyüdükçe tespit doğruluğu artarken, tespit edilebilen bölge büyüklüğü hassasiyetini kaybetmektedir. CNN tabanlı yöntemde ise pencere boyutunun büyümesinin daha iyi sonuç üreteceği yargısı CNN modeline, parametrelerine ve eğitim verisine bağlı olduğundan net bir şekilde söylenemez. Yapılan karşılaştırma neticesinde 3 kamera cihazından 2 tanesinde oldukça büyük bir farkla CNN tabanlı kamera model sinıflandırıcısı klasik PRNU yöntemine göre daha başarılı çalışmıştır. Geriye kalan bir adet kamera cihazında ise hemen hemen aynı performansı göstermiştir. Seçilen pencere boyutunun küçük olmasının PRNU yönteminin başarısı aşağıya çekmesinden ötürü CNN tabanlı yöntem küçük pencere boyutunda daha iyi bir performans göstermektedir. Ancak Canon marka cihazın parmakizi $96 \times 96$ kadar küçük seçilen bir pencere boyutunda dahi kuvvetli çıkmaktadır. Bu durum tamamen cihazın sensörlerinin bırakmış olduğu izler ile alakalıdır. Bu sebepten ötürü Canon 
marka cihazda PRNU yöntemi, CNN tabanlı yöntemden daha düşük ancak hemen hemen yakın bir performans göstermektedir. Bu sonuçlara göre CNN tabanlı yöntemin $96 \times 96$ gibi küçük boyuttaki pencerelerde daha başarılı bir yöntem olduğu söylenebilir. Karşılaştırılan bu iki yöntemin kameranın farklı özelliklerinden faydalanarak sonuç ürettiğini baz alarak gelecek çalışmamızda bu iki yöntemin birleştirilerek daha iyi bir tespit edici yapılması planlanmaktadır.

\section{KAYNAKLAR}

1. Bayar, B., \& Stamm, M. C. (2016, June). A deep learning approach to universal image manipulation detection using a new convolutional layer. In Proceedings of the 4th ACM Workshop on Information Hiding and Multimedia Security (pp. 5-10). ACM. DOI:10.1145/2909827.2930786

2. Bondi, L., Baroffio, L., Güera, D., Bestagini, P., Delp, E. J., \& Tubaro, S. (2017). First steps toward camera model identification with convolutional neural networks. IEEE Signal Processing Letters, 24(3), 259-263. DOI: 10.1109/LSP.2016.2641006

3. Bondi, L., Güera, D., Baroffio, L., Bestagini, P., Delp, E. J., \& Tubaro, S. (2017). A preliminary study on convolutional neural networks for camera model identification. Electronic Imaging, 2017(7), 67-76. DOI: https://doi.org/10.2352/ISSN.24701173.2017.7.MWSF-327

4. Bondi, L., Lameri, S., Güera, D., Bestagini, P., Delp, E. J., \& Tubaro, S. (2017, July). Tampering detection and localization through clustering of camera-based CNN features. In 2017 IEEE Conference on Computer Vision and Pattern Recognition Workshops (CVPRW) (pp. 1855-1864). IEEE. DOI: 10.1109/CVPRW.2017.232

5. Dirik, A. E., \& Memon, N. (2009, November). Image tamper detection based on demosaicing artifacts. In Image Processing (ICIP), 2009 16th IEEE International Conference on (pp. 1497-1500). IEEE. DOI: 10.1109/ICIP.2009.5414611

6. Farid, H. (2009). Exposing digital forgeries from JPEG ghosts. IEEE transactions on information forensics and security, 4(1), 154-160. DOI: 10.1109/TIFS.2008.2012215

7. Ferrara, P., Bianchi, T., De Rosa, A., \& Piva, A. (2012). Image forgery localization via finegrained analysis of CFA artifacts. IEEE Transactions on Information Forensics and Security, 7(5), 1566-1577. DOI: 10.1109/TIFS.2012.2202227

8. Gloe, T., \& Böhme, R. (2010, March). The'Dresden Image Database'for benchmarking digital image forensics. In Proceedings of the 2010 ACM Symposium on Applied Computing (pp. 1584-1590). ACM. Doi:10.1145/1774088.1774427

9. Goljan, M., Fridrich, J., \& Filler, T. (2009, February). Large scale test of sensor fingerprint camera identification. In Media Forensics and Security (Vol. 7254, p. 72540I). International Society for Optics and Photonics. Doi: 10.1117/12.805701

10. Krawetz, N., \& Solutions, H. F. (2007). A Picture's Worth... Hacker Factor Solutions, 6.

11. Lin, Z., He, J., Tang, X., \& Tang, C. K. (2009). Fast, automatic and fine-grained tampered JPEG image detection via DCT coefficient analysis. Pattern Recognition, 42(11), 24922501. Doi:https://doi.org/10.1016/j.patcog.2009.03.019

12. Liu, Y., Guan, Q., Zhao, X., \& Cao, Y. (2018, June). Image forgery localization based on multi-scale convolutional neural networks. In Proceedings of the 6th ACM Workshop on Information Hiding and Multimedia Security (pp. 85-90). ACM. Doi:10.1145/3206004.3206010 
13. Lukas, J., Fridrich, J., \& Goljan, M. (2006). Digital camera identification from sensor pattern noise. IEEE Transactions on Information Forensics and Security, 1(2), 205-214. DOI: $10.1109 /$ TIFS.2006.873602

14. Tuama, A., Comby, F., \& Chaumont, M. (2016, December). Camera model identification with the use of deep convolutional neural networks. In Information Forensics and Security (WIFS), 2016 IEEE International Workshop on (pp. 1-6). IEEE. DOI: 10.1109/WIFS.2016.7823908

15. Vedaldi, A., \& Lenc, K. (2015, October). Matconvnet: Convolutional neural networks for matlab. In Proceedings of the 23rd ACM international conference on Multimedia (pp. 689692). ACM. Doi:10.1145/2733373.2807412

16. Ye, S., Sun, Q., \& Chang, E. C. (2007, July). Detecting digital image forgeries by measuring inconsistencies of blocking artifact. In Multimedia and Expo, 2007 IEEE International Conference on (pp. 12-15). IEEE. DOI: 10.1109/ICME.2007.4284574 
